\title{
Application of the TEVA-SPOT in designing the monitoring of water networks
}

\author{
Alicja Bałut $^{1, *}$, and Andrzej Urbaniak $^{2}$ \\ ${ }^{1}$ Insitute of Environmental Engineering, Poznań University of Technology, ul. Berdychowo 4, 60-151, Poznań, Poland \\ ${ }^{2}$ Institute of Computing Science, Poznań University of Technology, ul. Piotrowo 2, 60-965, Poznań, Poland
}

\begin{abstract}
TEVA-SPOT software was released in 2008 as a freeware dedicated to water and sewer utilities. It enables modelling of various of measurement points, and built-in tools to conduct more in-depth examinations. This paper presents selected possibilities this program grants in the context of emergencies, terrorist attacks or if it is used as an early warning system. It had gone through a hands-on examination and its results- advantages, difficulties and limitations have as well been described here.
\end{abstract}

\section{Introduction}

Consideration of intentional threats that are introduced into a water network on purpose should consider the fact that they may appear at any given spot. Recently it has been raised that water poisoning may be one of terrorists' top 'tactics' due to its relative low cost and, on other end, significant financial, social and psychological losses [1].

Our motivation behind this issue is modern IT solutions dedicated to the management of water and sewage utilities, especially in the area of water networks' hydraulic modelling and early warning systems. Companies even if equipped in expanded platforms and dedicated solutions rarely utilize all their features. An often met problem of water and sewage utilities is lack of integration between geographic information systems, hydraulic modelling, monitoring, SCADA (Supervisory Control And Data Acquisition) system or accidents' recording across an entire company (water intake, filtration, finally distribution). This has been proven to be an issue of high importance, often the one that in case of critical situations decides on the success of the implementation of an integrated management system. It may turn out to be indispensable in critical situations.

Whilst designing an early warning system or a watersewage monitoring one a broad spectrum of applications of collected data should be considered - not only in order to support their management but primarily to guarantee a fast response and action in case of a threat a terrorists' attach - even if at present it does not seem likely.

\section{Characteristics of the TEVA-SPOT program}

TEVA-SPOT (Threat Ensemble Vulnerability Assessment-Sensor Placement Optimization Tool) is the result of research made by National Homeland Security Research Center (NHSRC) in the US that has been realizing scientific research programs since 2002 oriented at i.e. network infrastructure security of United States Environmental Protection Agency (US-EPA). This has been led by researchers from US-EPA, Sandia National Laboratories, Argonne National Laboratory and University of Cincinnati [2]. Over the last several dozens of years US-EPA with support of NHSRC and other research centres has released a range of IT tools dedicated to environment protection, including, i.e. the following programs: CANARY, EPANET -MSX and TEVA-SPOT [3]. TEVA-SPOT was released in 2008 as a freeware; it was dedicated to water and sewage utilities. Its user interface is available only in English. It enables modelling of various scenarios of events that originate from contaminations spreading in water networks. It supports analysis of such events, localization of measurement point and more detailed research addressed in the following chapters of this paper.

\subsection{Structure of the program}

Functional structure of TEVA-SPOT is based on three key modules:

- First module enables various simulations of incidents in the system that is being designed (described as 'ensemble'). Classification of a single incident may depend on the type of contamination, its amount (dose of the substance), with pointed spot of introduction or contamination, registered time of insertion or detection in a water network.

- Second module is dedicated to forecasting potential effects of detected contamination from the perspective of public health and water network's security.

- Third module runs on multi-criteria optimization methods in order to determine optimal localization of

Corresponding author: alicja.balut@put.poznan.pl 
measurement point whilst minimizing threats for public security and costs and costs [3].

Table 1 presents a set of data that are indispensable as input criteria for calculations performed by TEVASPOT. This application can either be used as an add-on, a toolkit for EPANET or as a standalone program with its own user interface that is interfaced with EPANET and utilizes an existing hydraulic model of a water network. The performance of TEVA-SPOT is based on the probability analysis of multiple possible contamination events.

Table 1. Information and data required to design the localization of measurement points using TEVA-SPOT [3].

\begin{tabular}{|c|c|}
\hline Data type & Description \\
\hline $\begin{array}{c}\text { Model of a water } \\
\text { network }\end{array}$ & $\begin{array}{c}\text { A hydraulic model, a inp file } \\
\text { that performs correctly, where } \\
\text { simulations within the 7-10 days } \\
\text { can be executed, calibrated. }\end{array}$ \\
\hline $\begin{array}{c}\text { Characteristics of } \\
\text { measuring } \\
\text { equipment }\end{array}$ & $\begin{array}{c}\text { Type of equipment, way of } \\
\text { probing, ranges of operation, } \\
\text { existing system of threats } \\
\text { detection, installation cost. }\end{array}$ \\
\hline $\begin{array}{c}\text { Designing potential } \\
\text { threats }\end{array}$ & $\begin{array}{c}\text { Data depicting threat that needs } \\
\text { to be detected: a list of potential } \\
\text { contaminants, their behaviour, } \\
\text { way of propagation in the } \\
\text { network, reaction to water. }\end{array}$ \\
\hline $\begin{array}{c}\text { Measurements } \\
\text { Reaction and } \\
\text { feedback from the } \\
\text { water and sewage } \\
\text { utilities }\end{array}$ & $\begin{array}{c}\text { Substance detection time, area } \\
\text { and precise localisation, set of } \\
\text { people at risk. }\end{array}$ \\
\hline $\begin{array}{c}\text { Potential sites for } \\
\text { measurement point }\end{array}$ & $\begin{array}{c}\text { Reaction plan: total time } \\
\text { required to limit further } \\
\text { exposure of public health at risk. } \\
\text { of the hydralled based on nodes }\end{array}$ \\
\hline
\end{tabular}

The procedure starts with an upload of the file with the hydraulic model. Next, scenarios of possible events and their range, dependent on multiple hydraulic and quality parameters have to be manually defined in the program. Hydraulic calculations are executed in the next step where results derive directly from EPANET's computational engine. These data, saved as files, form the basis for an estimation of an influence on public health and an assessment of an influence of a selected threat on the performance of an analysed water distribution network. The following part of this paper present methodology that has been adopted as well as the procedure how calculations are performed. Data declaration method has been presented at Fig. 1.

\section{The potential of TEVA-SPOT from the perspective of analyses it executes}

The structure of TEVA-SPOT is sophisticated and based on modules where each is accountable for a set of functions. Every module reads multiple parameters that have to be defined.

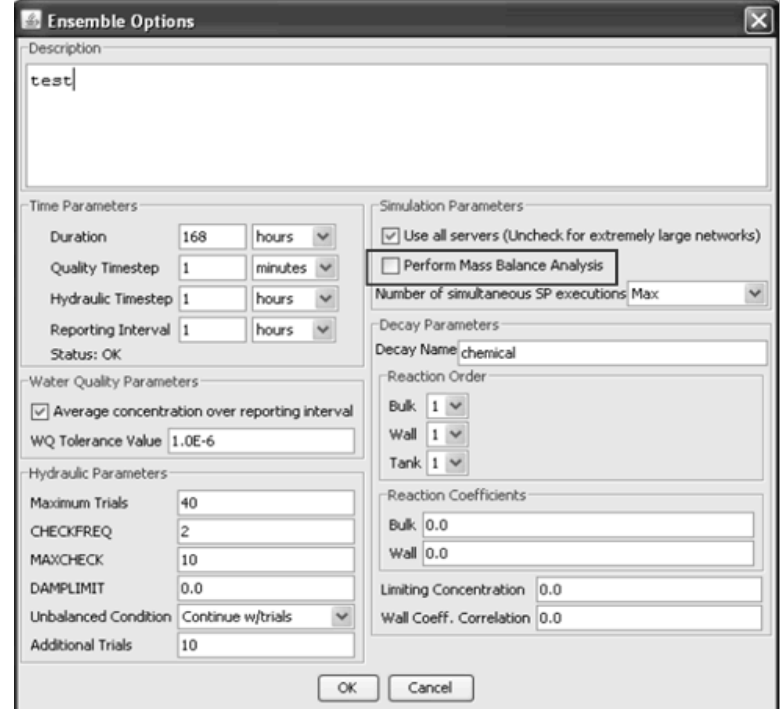

Fig. 1. A screenshot from TEVA-SPOT that presents a view to define basic parameters for threat calculations [4].

Only after all of them that are required to execute calculations have been confirmed, the status bar with available analyzes turns red and they can be executed (Fig. 2).

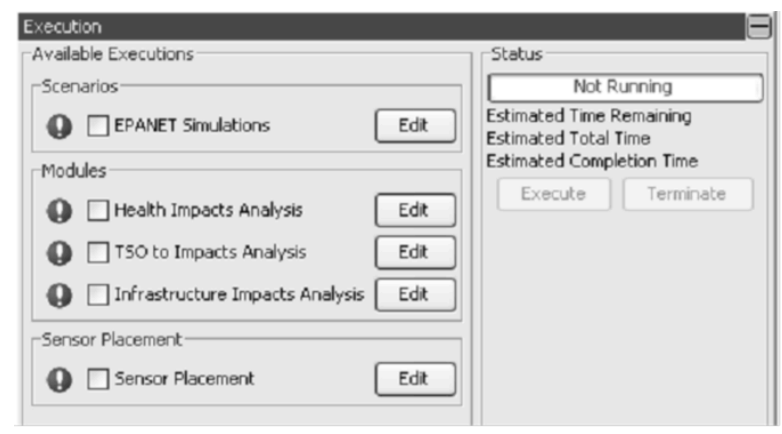

Fig. 2. A screenshot from TEVA-SPOT and the calculation panel for all modules [5].

\subsection{Analysis of threat's influence on a water network}

Thanks to the IIA module (Infrastructure Impact Analysis) TEVA-SPOT enables analyses of scenarios influence of threats on network's infrastructure. For every localisation of the detected threat the sum of sections is calculated where concentration of the contamination exceeds the maximum value threshold that had been declared in $\mathrm{mg} / \mathrm{L}$. The IIA module supports calculations of sections' length and planning of the sequence of network's rinsing.

\subsection{Analysis of threat's influence on a public health}

The HIA module (Health Impact Analysis) makes it possible to assess effects of threats on public health, with respect to contamination detected in individual nodes of the model. HIA can also serve as the platform of 
detailed information, provided to it beforehand, of analyzed substances and their influence on public health.

At the beginning of the calculation process each threat has to be classified into one of three groups: chemical, toxic, biological. Then, dependent upon the type of the threat a series of factors has to be declared, i.e.: lethal dose (LD) - contaminant's concentration that results in the death of $50 \%$ of the population; infectious dose (ID) - sickness or infection of its $50 \%$.

Prior to the initiation of calculations average statistical data of a consumer have to be declared: their weight and daily consumption (default value 1.41 litre). Additionally in case of biological threats a degree of delay has to be stated, being timespan between threat's detection and infection. Fig. 3 presents a sample view with these data.

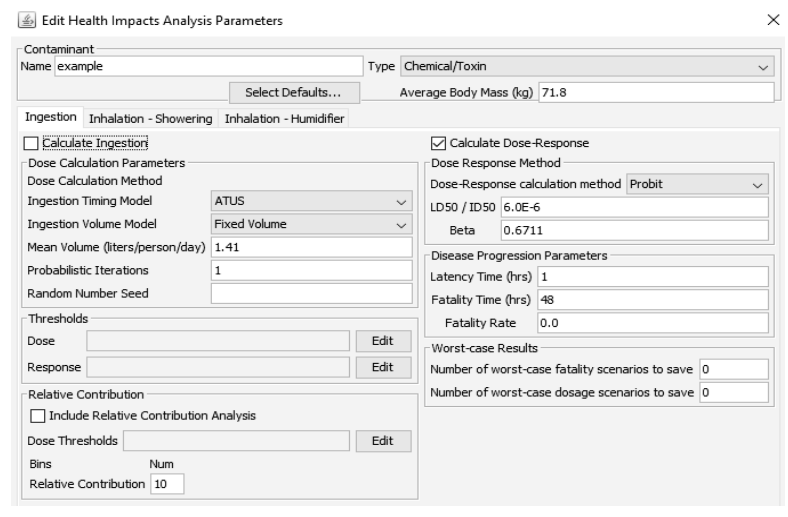

Fig. 3. Data required to run HIA analysis in TEVA-SPOT [5].

To complete the analysis of threat's influence on public health it is required to assign a number of inhabitants consuming water to each node (exposed to consumption of this substance). These actions are undertaken via the 'population analysis' module. Calculation if the population is based on water consumption values, data from billing systems or individual consumption of water, calculated per property [5].

\subsection{Analysis of the localisation of measurement points}

Analysis of the measurement point localisation is a classical optimisation issue where multiple criteria, limitations and solutions are possible. Choice of these localisation spots has been divided in TEVA-SPOT into a few stages: a) simulation of contamination, b) its influence on public health and network infrastructure, c) multi-criteria optimization that is based on an assignment of weights to criteria. It is possible to simultaneously analyze a few events. Received input data are EPANET results of calculations on hydraulic models as well as files with results of analysis carried within HIA and IIA modules [5].

Localisation of measurement point should take into account users' preferences and ability to install measuring devices [2]. A parameter of significance is assigned to each localization or its preference related to a few analyzed points (perspective of greater probability of pollution). So called expert knowledge, ranking methods (preferences of analyzed spots) and methods of multi-criteria optimization have been applied into this module. TEVA-SPOT gives an option to choose a calculation method [6]:

- Mixed-Integer Programming (MIP) - method that when run for larger networks may seriously consume internal memory.

- Greedy Randomized Adaptive Search Procedure (GRASP) that applies heuristic algorithms. It is efficient when used in case of larger networks yet it demands the problem to be reduced beforehand via shortened list of potential localisations as well as through limitation of simultaneously simulated network threats that is realized during models' skeletisation.

- Lagrange's method of extended multipliers (LAG) although this method is faster than GRASP, received solutions - precise localisations are not as close to optimal solutions as they are when heuristic methods were applied. This method is used in case of extensive water networks or when available memory is too limited for the GRASP method.

\section{TEVA-SPOT in Practice}

Application of TEVA-SPOT with a graphical user interface requires earlier installation of two minor programs that support Python as the programming language plus files with JAVA add-ons.

\subsection{Ways of presenting results}

The TEVA-SPOT program enables creation of various maps, tables and charts that present results of threats' influence calculation on public health as well optimization of the localization of measurement point [7].

Key elements have been listed below: a) maps with estimated fatality at areas impacted by the threat, b) maps of greatest influence on public health, expressed as a ' $\mathrm{C}$ ' numerical value for the contaminant, c) a table with all water network objects listed by the ' $C$ ' value that presents an influence of this threat on all items, d) population maps for all network nodes, e) map containing proposed localisations of measurement point.

Result data can be exported into .mdb/.xls files and when they are needed they can be imported into GIS systems.

\subsection{Advantages and drawbacks}

For this type of an application, based on calculations realized in the HIA, IIA and RA modules of TEVASPOT for a selected theoretical threat, the following list of advantages and limitations have been observed. Testing has been realized at a sample mid-size hydraulic model that had been provided by the software's manufacturer, and a few own similar models. Advantages and drawbacks that have been listed in Table 2 represent the practical aspect of TEVA-SPOT's 
application and an assessment of user interface with special focus on threat scenarios modelling. First implementation of the program in Poland to localize measurement point is already foreseen. This would give chances for its enhanced assessment from the perspective of a real hydraulic model of a medium-size town in Poland.

Table 2. Advantages and limitations in applying the TEVASPOT program.

\begin{tabular}{|c|c|}
\hline Advantages & Limitations \\
\hline $\begin{array}{c}\text { Program enables } \\
\text { results' assessment } \\
\text { of an event, } \\
\text { expressed ie. in a } \\
\text { number of injured } \\
\text { persons and length } \\
\text { of networks } \\
\text { sections that } \\
\text { require rinsing. }\end{array}$ & $\begin{array}{c}\text { Quality of received data depends } \\
\text { on model's quality and its } \\
\text { calibration. It is advised to } \\
\text { additionally include its } \\
\text { representativeness over a year } \\
\text { (suggested analysis of two } \\
\text { models that include average data } \\
\text { for summer and winter seasons. }\end{array}$ \\
$\begin{array}{c}\text { The authors have } \\
\text { underlined that the } \\
\text { computational } \\
\text { engine is fully } \\
\text { scalable what } \\
\text { reduces required } \\
\text { disc space and } \\
\text { operations' runtime } \\
\text { to minimum [8]. }\end{array}$ & $\begin{array}{c}\text { Lack of any single parameter in } \\
\text { the module makes it impossible } \\
\text { to proceed with calculations. For } \\
\text { models that contain above } \\
\text { 10.000 nodes and where a few } \\
\text { scenarios have been built } \\
\text { calculations can take from over a } \\
\text { dozen to a few dozen minutes. }\end{array}$ \\
\hline $\begin{array}{c}\text { Each module } \\
\text { makes it possible to } \\
\text { focus on the } \\
\text { modelling method } \\
\text { and data values. }\end{array}$ & $\begin{array}{c}\text { Use of the „Execution panel” } \\
\text { view is not handy and does not } \\
\text { always work as expected. } \\
\text { Authors have pointed out cases } \\
\text { where issues can occur. }\end{array}$ \\
\hline $\begin{array}{c}\text { Integrity with the } \\
\text { EPANET program }\end{array}$ & $\begin{array}{c}\text { Lack of settings' convergence } \\
\text { for both applications may lead to } \\
\text { errors in calculations performed } \\
\text { in TEVA-SPOT. Lack of a direct } \\
\text { connection with a GIS platform } \\
\text { that provided results to be } \\
\text { displayed by crisis management } \\
\text { services. }\end{array}$ \\
\hline $\begin{array}{c}\text { Threats' definition is difficult } \\
\text { due to a lack of research on } \\
\text { parameters that characterize } \\
\text { substances. This task requires } \\
\text { substantial expert knowledge } \\
\text { and includes not only details } \\
\text { relevant to seasons yet as well } \\
\text { local conditions of sites where } \\
\text { these substances could be }\end{array}$ \\
\hline
\end{tabular}

\section{Conclusions}

Solution that has been presented in this paper discusses the oldest IT application that enables simulations of threats and assessment of their impact on water network's integrity. It definitely is a vital supplement to early warning systems and it does contain methodology what actions should be undertaken to design localisation of measurement point in a monitoring system. This article as well addresses potential difficulties, especially for readers who have never before had any experiences with water networks' modelling in EPANET.

According to the authors of TEVA-SPOT, U.S. Environmental Protection Agency has already initiated co-operation with producers of commercial IT solutions aiming at the deployment of analyses discussed in this paper into basic tools of water networks' hydraulic modelling [8].

Limitations that have been presented, that focus on methods of the definition of threats and threshold values, point at the sound requirement to continue research on specific substances' behaviour in various types of water networks, also considering seasoning and individual features of a given one.

Issues that relate to application of IT tools into modelling and design of a monitoring system, that this article presents, are an example of effective use of software interfaced with EPANET. Other cases have been described in our earlier article [9].

\section{References}

1. G. Jelonek, Wod. i Kan. 3, 157 (2017)

2. https://www.epa.gov/aboutepa/about-nationalhomeland-security-research-center-nhsrc [Updated: 3, 2017]

3. Clark R.M., Hakim S., Ostfeld A., Handbook of Water and Wastewater Systems, (Protection Springer, USA, 2011)

4. EPA/600/R-08/147, US-EPA by Janke, R. Threat Ensemble Vulnerability Assessment- Sensor Placement Optimization Tool (TEVA-SPOT) Graphical User Interface User's Manual, NHSRC, Cincinnati, USA, 2012

5. EPA/600/R-09/141. Sensor Network Design for Drinking Water Contamination Warning Systems, A compendium of Research Result and Case Studies Using the TEVA-SPOT Software, NHSRC, Sandia National Laboratories, USA, 2010

6. A. Bałut, A. Urbaniak, Gaz Woda 9 (2013)

7. EPA/600/R-14/433, US-EPA by R. Janke, Application of TEVA-SPOT for Prioritizing Security Enhancements at Utility Facilities and for Protection of Critical Facilities, USA, Nov. 2014

8. R. Janke, TEVA-SPOT: Designing Contamination Warning Systems, Michigan Department of Environmental Quality, NHSRC/US EPA, USA, no. 9

9. A. Bałut, A. Urbaniak, Proc. of ICCC' 2016, Ivo Petráš - Igor Podlubny - Ján Kačur (eds.), (Tatranska Lomnica, Slovakia, 2016) 